\title{
Determinants of Premature Atherosclerosis in Children With End- Stage Renal Disease
}

\author{
H. M. DVOŘÁKOVÁ ${ }^{1,2}$, P. SZITÁNYI ${ }^{3}$, P. DVOŘÁK ${ }^{4}$, J. JANDA $^{5}$, T. SEEMAN ${ }^{5}$, J. ZIEG $^{5}$, \\ V. LÁNSKÁ ${ }^{6}$, K. KOTAŠKA ${ }^{7}$, J. PIŤHA ${ }^{1}$
}

${ }^{1}$ Laboratory for Atherosclerosis Research, Institute of Clinical and Experimental Medicine, Prague, Czech Republic, ${ }^{2}$ Department of Neonatology, University Hospital Prague-Motol, Prague, Czech Republic, ${ }^{3}$ Department of Pediatrics and Adolescent Medicine, University General Teaching Hospital, Prague, Czech Republic, ${ }^{4}$ Department of Pediatrics, Thomayer University Hospital, Prague, Czech Republic, ${ }^{5}$ Department of Pediatrics, University Hospital Prague-Motol, Prague, Czech Republic, ${ }^{6}$ Department of Statistics, Institute of Clinical and Experimental Medicine, Prague, Czech Republic, ${ }^{7}$ Department of Clinical Biochemistry and Pathobiochemistry, University Hospital Prague-Motol, Prague, Czech Republic

Received November 25, 2010

Accepted August 24, 2011

On-line December 20, 2011

\section{Summary}

Cardiovascular disease is a major cause of morbidity and mortality in young adults with end-stage renal disease (ESRD), but its basis is still not well understood. We therefore evaluated the determinants of atherosclerosis in children with ESRD. A total of 37 children with ESRD (with 31 who had undergone transplantation) were examined and compared to a control group comprising 22 healthy children. The common carotid intimamedia thickness (CIMT) was measured by ultrasound as a marker of preclinical atherosclerosis. The association of CIMT with anthropometrical data, blood pressure, plasma lipid levels, and other biochemical parameters potentially related to cardiovascular disease was evaluated. Children with ESRD had significantly higher CIMT, blood pressure, and levels of lipoprotein (a), urea, creatinine, ferritin, homocysteine, and serum uric acid as well as significantly lower values of apolipoprotein A. The atherogenic index of plasma (log(triglycerides/HDL cholesterol)) was also higher in patients with ESRD; however, this difference reached only borderline significance. In addition, a negative correlation was found between CIMT and serum albumin and bilirubin in the ESRD group, and this correlation was independent of age and body mass index. In the control group, a significant positive correlation was observed between CIMT and ferritin levels. Factors other than traditional cardiovascular properties, such as the antioxidative capacity of circulating blood, may be of importance during the early stages of atherosclerosis in children with endstage renal disease.

\section{Key words}

Atherosclerosis - Children - Carotid intima-media thickness • End-stage renal disease

\section{Corresponding author}

Hana M. Dvořáková, Department of Neonatology, University Hospital Prague-Motol, V Úvalu 84, 15006 Praha 5, Czech Republic. E-mail: dvorakovahm@centrum.cz

\section{Introduction}

Despite an improvement in the survival of children with severe chronic kidney disease, morbidity and mortality rates in these patients are still relatively high. The risk of death due to cardiovascular disease (CVD) in children with end-stage renal disease (ESRD) is 1,000 -fold higher than in the general pediatric population (Kavey et al. 2006). After successful renal transplantation, the risk of CVD decreases considerably in children; nevertheless, it remains at least two-fold higher compared to the age-matched general population (Sarnak et al. 2003, Mitsnefes 2008).

Complications due to atherosclerosis, the main 
cause of death in adult ESRD populations, are rather rare in pediatric patients. A total of 1,380 deaths (for patients aged 0-30 years) recorded by the United States Renal Data System between 1990 and 1996 were analyzed in a recent study (Parekh et al. 2002), and the authors found that the main causes of cardiovascular deaths in this study were sudden cardiac arrest, arrhythmia and cardiomyopathy. However, CVD of atherosclerotic origin has been shown to be the main cause of morbidity and mortality in young adults with ESRD (Berenson 2002, Oh et al. 2002, Oren et al. 2003, McDonald et al. 2004). Based on these observations, numerous studies have focused on the potential determinants of the extreme acceleration of atherosclerosis in patients with renal impairment. There is no doubt that renal replacement therapy contributes to specific proatherogenic factors such as chronic inflammation (due to catheters, dialysate leakage, chronic or recurrent infections during immunosuppression, raised cytokine production and reduced renal clearance) and hypertension or aggressive pharmaceutical treatment (steroids, immunosuppressives) (Lilien et al. 2003). The availability of high-resolution ultrasonographic methods has enabled non-invasive investigation of functional and morphological atherosclerotic changes in childhood (Sass et al. 1998, Yang et al. 2007, Jehlicka et al. 2009). The common carotid intima-media thickness (CIMT), as measured by ultrasound, is the most frequently used marker of preclinical atherosclerosis. Normative values of CIMT have already been proposed based on the examination of 247 healthy children (Jourdan et al. 2005). However, only a few studies have been published on preclinical atherosclerosis in pediatric ESRD patients with respect to the broad range of metabolic risk factors. These studies have revealed unequivocal findings of increased preclinical atherosclerosis in peripheral arteries (Mitsnefes et al. 2004, Litwin et al. 2005, Jourdan et al. 2005, Poyrazoglu et al. 2006, Bilginer et al. 2007, Civilibal et al. 2007).

The Czech Republic ranks among the countries with the highest incidence of CVD, caused by a high prevalence of cardiovascular risk factors including children (Urbanová et al. 1998). Therefore, the aim of our study was to detect determinants of atherosclerosis in children with ESRD from the high-risk Czech population. The particular aims of this study were as follows: to evaluate the presence of preclinical atherosclerosis in children with ESRD and to detect conventional and newly discussed determinants of preclinical atherosclerosis in this population.

\section{Methods}

Thirty-seven children (20 boys and 17 girls, aged $14.5 \pm 3.3$ years) with ESRD who were undergoing renal replacement therapy (RRT) were examined. The study group consisted of 31 children that had undergone successful renal transplantation and 6 that had undergone peritoneal dialysis (PD). The renal diseases diagnosed in the study group were as follows: hereditary nephropathies $(n=11)$, renal hypo- or dysplasia $(n=6)$, glomerulonephritis $(\mathrm{n}=3)$, tubulointerstitial nephritis $(n=3)$, obstructive nephropathy $(n=2)$, reflux nephropathy $(n=2)$, hemolytic-uremic syndrome $(n=1)$, and unknown causes $(n=2)$. All dialysed children were treated with continuous cycling peritoneal dialysis. None of the children suffered from diabetes mellitus, and no child was treated with any lipid-reducing medication. Thirty-four children (92\%) in the study group were treated for high blood pressure (BP). In the transplant group, only four children were treated with vitamin D analogues, and none were treated with phosphate binders. All children from the PD group were treated with phosphate binders, and four members of the PD group were given vitamin D analogues as well. The mean time between RRT and ultrasound examination in the patient group was $4.4 \pm 2.7$ years, and the mean time between dialysis and transplantation was $12.5 \pm 11$ months.

The height and weight of each patient were measured using a standard protocol, and the body mass index (BMI) was calculated as (weight in $\mathrm{kg}$ )/(height in $\mathrm{m})^{2}$. The office systolic blood pressure (SBP) and diastolic blood pressure (DBP) were measured using an Omron M5-1 automatic blood pressure monitor (Omron Corporation, Kyoto, Japan) with an appropriately sized cuff on the right arm of the seated patient after 5 minutes of rest. The mean arterial pressure was calculated as the diastolic pressure $+1 / 3$ (systolic - diastolic blood pressure). All anthropometrical and biochemical measurements, including BP, were obtained on the same day as the ultrasonic examination for preclinical atherosclerosis in the carotid arteries.

As a control group, 22 healthy, gender-matched children (10 boys and 12 girls, aged $11.0 \pm 4.4$ years) were included in the study and examined using the same protocols. The control group comprised healthy children of the hospital staff and patients from the allergology and gastroenterology outpatient clinics who were not 


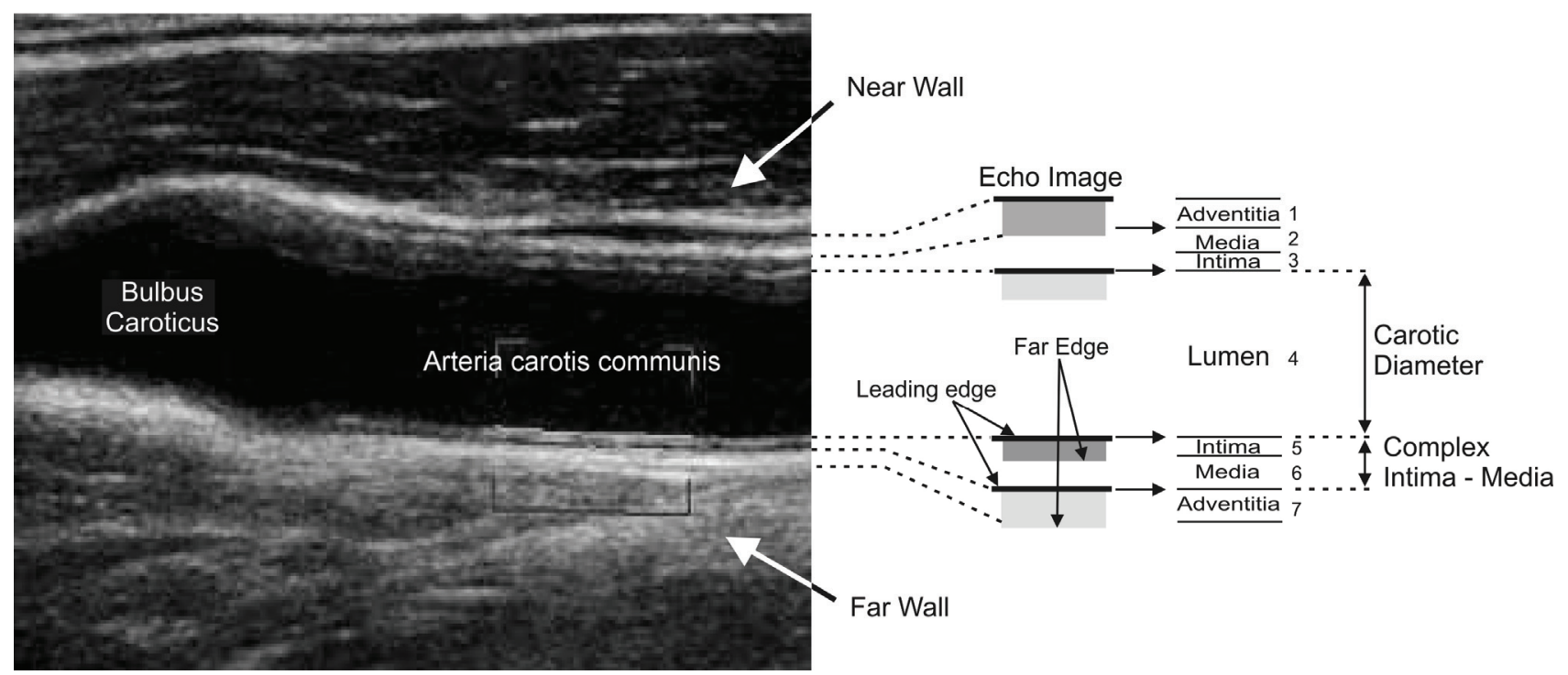

Fig. 1. Bifurcation of the common carotid artery ( 7 echo zones); measurements were performed between the leading edges of the far arterial wall (zones $5+6$ ).
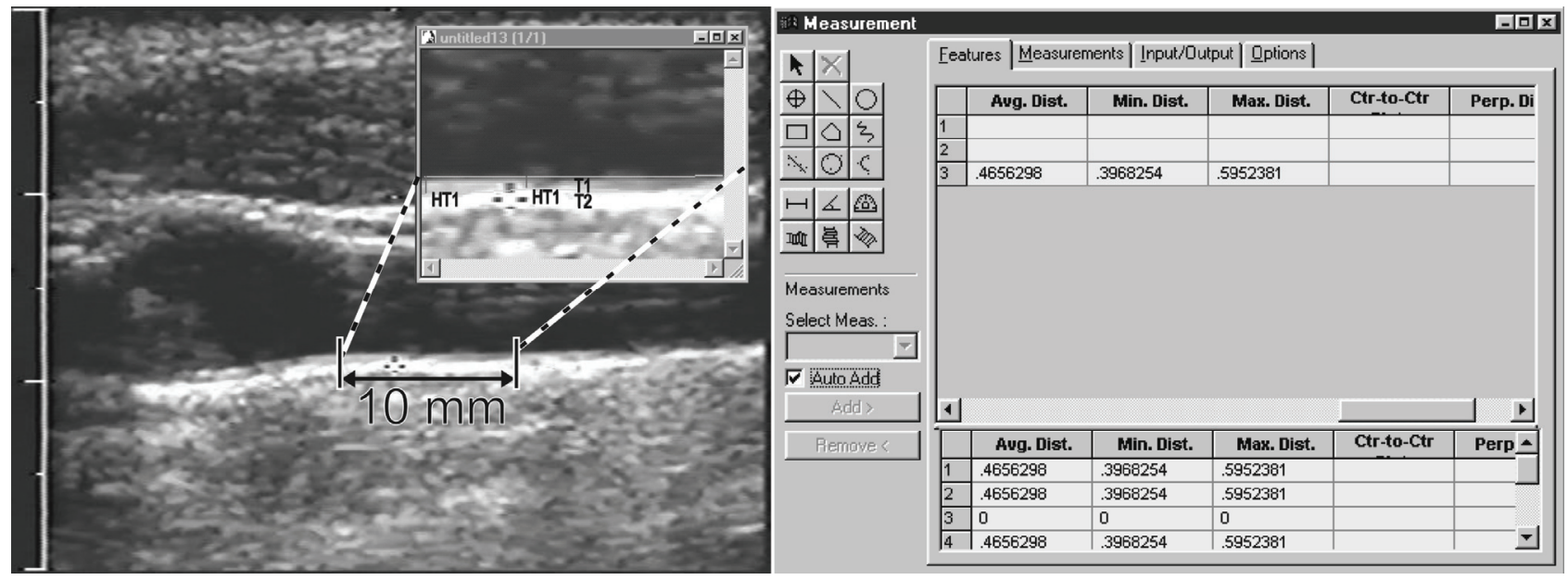

Fig. 2. Offline measurement of CIMT in a $10-\mathrm{mm}$-long segment of the common carotid artery.

undergoing systemic steroid therapy nor had been diagnosed with lipid metabolism disorders. The study protocol was approved by the local ethics committee of the Second Faculty of Medicine, Charles University, Prague, Czech Republic, and informed consent was obtained from the parents of all children involved in the investigation.

\section{Measurement of CIMT}

As a marker of atherosclerosis, CIMT was measured using a high-resolution ultrasonic device (SonoSite Titan, USA) with a 7.5-MHz linear transducer. This approach was a slight modification of a previously described method (Pitha et al. 1999). In brief, all measurements were performed on the far (deeper) wall of the common carotid artery, where the intima-media layer is defined as a space between the two visible leading edges (lumen-intima, media-adventitia) (Fig. 1), as was described and validated by Pignoli and others (Pignoli et al. 1986, Wendelhag et al. 1991, Raitakari 1999). In each patient, the CIMT of both left and right common carotid arteries was recorded, and the proper measurements were performed offline using computer software (ImagePro Plus, USA). The optimal image of each left and right common carotid artery was frozen, and 10-mm-long segments proximal to the carotid bifurcation were marked (Fig. 2). The mean IMT in the entire 10-mm-long segment was measured, and the final value was calculated as the arithmetical mean of the two measurements of the left and right carotid arteries. The coefficient of variation in previous studies was $4.9 \%$. 
Table 1. Anthropometrical, clinical, biochemical and ultrasonic characteristics in children with end-stage renal disease and control children. Data are given as mean \pm standard deviation or standard error.

\begin{tabular}{|c|c|c|c|c|c|}
\hline & $\begin{array}{l}\text { ESRD } \\
\mathbf{n}=\mathbf{3 7}\end{array}$ & $\begin{array}{c}\text { Transplant } \\
\text { patients }(\mathrm{Tx}) \\
\mathbf{n}=\mathbf{3 1}\end{array}$ & $\begin{array}{l}\text { Controls } \\
\qquad \mathbf{n}=\mathbf{2 2}\end{array}$ & $\begin{array}{c}\mathbf{p} \\
\text { ESRD } \\
\text { vs. control }\end{array}$ & 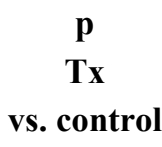 \\
\hline Age (years) & $14.6 \pm 3.3$ & $14.8 \pm 3.3$ & $11.0 \pm 4.4$ & 0.003 & 0.002 \\
\hline Boys/girls (n) & $20 / 17$ & $16 / 15$ & $10 / 12$ & NS & NS \\
\hline Carotid intima-media thickness (mm) & $0.45 \pm 0.04$ & $0.44 \pm 0.03$ & $0.38 \pm 0.03$ & $<0.001$ & $<0.001$ \\
\hline Body mass index $\left(\mathrm{kg} / \mathrm{m}^{2}\right) *$ & $20.0 \pm 0.7$ & $20.6 \pm 0.7$ & $19.4 \pm 0.9$ & NS & NS \\
\hline Systolic blood pressure $(\mathrm{mmHg})^{*}$ & $120 \pm 1.70$ & $120 \pm 1.90$ & $113 \pm 2.20$ & 0.027 & 0.047 \\
\hline Diastolic blood pressure $(\mathrm{mmHg}) *$ & $79 \pm 11.30$ & $78 \pm 10.60$ & $70 \pm 9.80$ & 0.003 & 0.006 \\
\hline Mean arterial pressure $(\mathrm{mmHg})^{*}$ & $93 \pm 1.60$ & $92 \pm 1.70$ & $85 \pm 2.10$ & 0.006 & 0.018 \\
\hline Serum total cholesterol $(\mathrm{mmol} / \mathrm{l})$ & $4.80 \pm 1.3$ & $4.60 \pm 0.9$ & $4.40 \pm 0.7$ & NS & NS \\
\hline Serum triglycerides $(\mathrm{mmol} / \mathrm{l}) *$ & $1.70 \pm 0.10$ & $1.70 \pm 0.10$ & $1.40 \pm 0.20$ & NS & NS \\
\hline Serum HDL cholesterol (mmol/l) & $1.21 \pm 0.31$ & $1.21 \pm 0.31$ & $1.32 \pm 0.30$ & NS & NS \\
\hline Serum LDL cholesterol (mmol/l) & $2.62 \pm 0.86$ & $2.56 \pm 0.65$ & $2.44 \pm 0.76$ & NS & NS \\
\hline $\begin{array}{l}\text { Atherogenic index of plasma } \\
(\log (\text { triglycerides } / H D L \text { cholesterol) }) *\end{array}$ & $0.11 \pm 0.05$ & $0.11 \pm 0.05$ & $-0.06 \pm 0.06$ & 0.036 & 0.051 \\
\hline Serum ApoB $(g / l)$ & $0.81 \pm 0.25$ & $0.78 \pm 0.16$ & $0.7 \pm 0.18$ & NS & NS \\
\hline Serum ApoAl $(g / l)$ & $1.23 \pm 0.21$ & $1.23 \pm 0.21$ & $1.34 \pm 0.18$ & 0.041 & 0.042 \\
\hline Lipoprotein (a) (mg/l) & $482 \pm 652$ & $449 \pm 688$ & $213 \pm 251$ & 0.031 & NS \\
\hline Serum C-reactive protein $(\mathrm{mg} / \mathrm{l})^{* *}$ & $1.13 \pm 1.75$ & $1.05 \pm 1.69$ & $0.63 \pm 0.42$ & NS & NS \\
\hline Serum urea (mmol/l) & $10.6 \pm 5.3$ & $9.8 \pm 5.1$ & $3.8 \pm 0.8$ & $<0.001$ & $<0.001$ \\
\hline Serum creatinine (mmol/l) & $223 \pm 203$ & $175 \pm 169$ & $67 \pm 15$ & $<0.001$ & $<0.001$ \\
\hline Glomerular filtration rate $\left(\mathrm{ml} / \mathrm{s} / 1.73 \mathrm{~m}^{2}\right)$ & $0.92 \pm 0.38$ & $1.16 \pm 0.27$ & $1.69 \pm 0.2$ & $<0.001$ & $<0.001$ \\
\hline Serum albumin $(g / l)$ & $45.6 \pm 4.6$ & $46.6 \pm 3.1$ & $46.3 \pm 3.7$ & NS & NS \\
\hline Serum ferritin $(\mu g / l)$ & $225 \pm 217$ & $188 \pm 196$ & $47 \pm 49$ & $<0.001$ & $<0.001$ \\
\hline Serum homocysteine $(\mu \mathrm{mol} / \mathrm{l}) *$ & $12.2 \pm 0.8$ & $12.4 \pm 0.8$ & $8.0 \pm 1.5$ & 0.024 & 0.022 \\
\hline Serum total bilirubin $(\mathrm{mg} / \mathrm{dl})^{*}$ & $9.6 \pm 1.3$ & $9.9 \pm 1.5$ & $13.1 \pm 1.8$ & NS & NS \\
\hline Serum uric acid $(\mathrm{mg} / \mathrm{dl})^{*}$ & $363 \pm 16$ & $370 \pm 18$ & $295 \pm 25$ & 0.024 & 0.022 \\
\hline Serum glucose $(\mathrm{mmol} / \mathrm{l})$ & $5.1 \pm 0.5$ & $5.1 \pm 0.5$ & $5.2 \pm 1.0$ & NS & NS \\
\hline
\end{tabular}

ESRD: end-stage renal disease; Tx: transplant subgroup of ESRD patients. * Adjusted for age; ** Four children from the ESRD/Tx group with C-reactive protein above $10 \mathrm{mg} / \mathrm{l}$ were excluded from the analysis

\section{Laboratory measurements}

A venous blood sample was drawn from each patient after an overnight fasting (12 hours). Total cholesterol, triglycerides, and cholesterol in all fractions were determined with a Hoffman-LaRoche COBAS MIRA autoanalyzer using enzymatic Boehringer Mannheim kits. Serum levels of urea, creatinine, albumin, total bilirubin, uric acid, and glucose were measured using enzymatic colorimetric reactions. Apolipoprotein A1 (ApoA1) and B (ApoB) were measured by an immunoturbidimetric method, and hs-C-reactive protein (CRP) was measured by a direct turbidimetric method with an Advia 1650 analyzer (Bayer, USA). Lipoprotein (a) (Lp(a)) was determined by immunonephelometric method on an Image 8000 analyzer (Beckmann Coulter, USA), homocysteine was measured using a fluorescence polarisation immunoassay with an IMx analyzer (Abbott, USA) and ferritin was measured by a chemiluminescence immunoassay on an Advia Kentaur analyzer (Bayer, USA). The atherogenic index of plasma (AIP) was calculated as the $\log$ (triglycerides/HDL cholesterol) according to Dobiasova and Frohlich (1991). Patients with values of hs-CRP protein above $10 \mathrm{mg} / \mathrm{l}$ were excluded from analysis (4 children in the ESRD group). The glomerular filtration rate was calculated by the Schwartz formula (Schwartz et al. 1976). 


\section{Statistical analysis}

Continuous variables are given as means with their standard deviations, and the standardization for age and BMI are presented as means with their standard errors. Discrete variables are given as absolute and relative frequencies. T-tests were applied for betweengroup comparisons of continuous variables, and the $\chi^{2}$ test was applied for discrete variables (e.g., boys/girls). To evaluate the differences between correlation coefficients in different groups, the test of equality of correlation coefficients was applied. All tests were twosided, and $\mathrm{p}<0.05$ was considered statistically significant. Because the children in the study group were significantly older than those in the control group, all significant differences were also adjusted for age.

\section{Results}

The main characteristics of the study and control groups are shown in Table 1, with separate analysis for transplant children alone. Because children with ESRD were older than those in the control group, the data were standardized for age when appropriate. Children with ESRD had a mean CIMT that was significantly higher than that of the control group. Regarding other variables studied, blood pressure, AIP, and levels of Lp(a), serum creatinine, ferritin, homocysteine, and serum uric acid were significantly higher in children with ESRD than in the control group. On the other hand, ApoA1 and, as expected, the glomerular filtration rate were significantly lower in children with ESRD than in the control group. No difference between the ESRD and control groups was found in the case of BMI or levels of serum total cholesterol, triglycerides, HDL cholesterol, LDL cholesterol, ApoB, hs-C-reactive protein, albumin, total bilirubin, or glucose. When the analysis was restricted to only children who had undergone transplantation, the atherogenic index of plasma and $\mathrm{Lp}$ (a) were no longer significantly different between the study and control groups, whereas the other results remained the same.

We subsequently analyzed the association between CIMT and the other variables studied in the group of transplanted children and in the control group (Table 2). All correlations were standardized for age and BMI. In the group of transplanted children, a significant negative correlation was found for serum albumin; in addition, if dialysed children were also included (data not shown), a significant negative correlation with total serum bilirubin was found $(\mathrm{r}=0.351, \mathrm{p}<0.05)$. In the control group, a significant positive correlation between CIMT and serum ferritin was found. No other significant correlation between CIMT and the factors under study was observed, including correlations between CIMT and indicators of calcium or phosphate metabolism (data not shown). Significantly different trends were found for the correlation of CIMT with diastolic blood pressure and mean arterial pressure in children with ESRD and those in the control group: the trend in the ESRD group was negative, whereas the trend was positive in the control group.

\section{Discussion}

\section{Presence of preclinical atherosclerosis}

In our study, we demonstrated increased preclinical atherosclerosis in children with end-stage renal disease compared to healthy control children from the high-risk Czech population. Our findings confirm the previously described presence of advanced preclinical atherosclerosis in children with ESRD. The CIMT values observed in the study and control groups were highly similar to those found in previous studies (Mitsnefes et al. 2004, Litwin et al. 2005, Jourdan et al. 2005, Poyrazoglu et al. 2006, Bilginer et al. 2007, Civilibal et al. 2007). In contrast, impaired distensibility of carotid arteries, but not increased CIMT, was observed in patients with ESRD in a study by Groothoff et al. (2002). However, older patients were included, and no metabolic factors were taken into account; therefore, this discrepancy could be explained by the different populations studied, including the control group, which also included relatives of the patients. This explanation is also supported by the higher carotid intimamedia thickness in this population as compared to the values reported in other studies, including the control group in this report.

\section{Conventional and nonconventional cardiovascular risk factors}

Regarding conventional cardiovascular risk factors, blood pressure and markers of reverse cholesterol transport were less favourable in our study group than in children with normal renal function. Regarding nonconventional cardiovascular risk factors, higher levels of homocysteine and ferritin were found in the children with ESRD than in the control children. However, in the case of homocysteine, these differences were almost assuredly due to decreased renal function, whereas the higher ferritin levels were due to prior substitution or treatment. 
Table 2. Partial correlation of intima-media thickness with cardiovascular risk factors and other selected parameters in children with end-stage renal disease after transplantation and in the control group adjusted for age and body mass index.

\begin{tabular}{lccc}
\hline & Transplant patients & Controls & $\begin{array}{c}\text { Equality of correlation } \\
\text { coefficients }\end{array}$ \\
& $\mathbf{n = 3 1}$ & $\mathbf{n = 2 2}$ & $\mathbf{p}$ \\
\hline Systolic blood pressure & -0.025 & 0.301 & 0.270 \\
Diastolic blood pressure & -0.308 & 0.285 & 0.044 \\
Mean arterial pressure & -0.239 & 0.340 & 0.049 \\
Total cholesterol & -0.131 & 0.139 & 0.372 \\
Triglycerides & -0.100 & 0.283 & 0.202 \\
HDL cholesterol & -0.071 & -0.291 & 0.460 \\
LDL cholesterol & -0.089 & 0.249 & 0.267 \\
Atherogenic index of plasma & -0.176 & 0.348 & 0.083 \\
(log(triglycerides/HDL cholesterol)) & & & \\
Apolipoprotein B & -0.030 & 0.400 & 0.150 \\
Apolipoprotein A1 & -0.176 & 0.087 & 0.370 \\
L (a) & -0.171 & -0.093 & 0.801 \\
C-reactive protein & 0.070 & -0.094 & 0.657 \\
Fasting serum glucose & -0.022 & 0.263 & 0.494 \\
Serum creatinine & 0.027 & -0.100 & 0.676 \\
Serum albumin & $-0.422^{*}$ & -0.250 & 0.239 \\
Serum ferritin & 0.049 & $0.609 *$ & 0.080 \\
Serum homocysteine & 0.242 & -0.091 & 0.401 \\
Serum bilirubin & $-0.300^{* *}$ & -0.017 & 0.345 \\
Serum uric acid & 0.087 & -0.461 & 0.075 \\
\hline
\end{tabular}

$* p<0.05 ; * * p<0.05$ if children on dialysis were also included (total number $=37$ )

Higher values of blood pressure in children with ESRD, despite frequent antihypertensive treatments, have already been described in several studies (Mitsnefes et al. 2004, Seeman et al. 2004, Poyrazoglu et al. 2006), and it is likely that this finding is primarily due to renal disease and immunosuppressive drugs (steroids).

Regarding dyslipidemia, we only found less favorable values for markers of reverse cholesterol transport, in particular, lower values for ApoA1 and the atherogenic index of plasma. The atherogenic index of plasma was of borderline significance when only children with transplant kidney were included; therefore, the generalisability of this finding is unclear. Many different changes in the spectrum, composition, and metabolism of lipoproteins have been described in patients with chronic kidney disease; these changes vary not only between different types of renal replacement therapy but also between various published studies. The most frequent pathological findings regarding the lipid spectrum in patients with renal impairment are hypertriglyceridemia, low HDL cholesterol, and a reduction in the size of LDL particles. The majority of studies have shown that neither the synthesis nor secretion of lipoproteins is significantly affected by renal insufficiency (Querfeld 1993). Some studies have explained changes in lipoprotein levels (uremic dyslipidemia) by decreased catabolism of lipoproteins containing apoB (Querfeld 1993, Kronenberg et al. 1996, Attman et al. 1997). In addition, the correlation between cardiovascular-related death and hyperlipidemia in patients with chronic renal insufficiency has not been demonstrated, although the lipid profile in these patients has been found to be markedly atherogenic. One of the most frequently discussed confounding factors in patients with renal failure is malnutrition associated with low cholesterol levels (Ritz 1996).

Other differences between the study and control groups were obviously related to lower glomerular filtration rate (serum urea, homocysteine, and uric acid) and/or treatment for the disease (ferritin). 


\section{Determinants of preclinical atherosclerosis}

The main determinants of preclinical atherosclerosis in children with ESRD were lower levels of albumin and bilirubin. In contrast, only ferritin strongly and positively correlated with preclinical atherosclerosis in children with normal renal function. No significant association between preclinical atherosclerosis and conventional cardiovascular risk factors was found in any group.

Our finding regarding the inverse relationship between CIMT and albumin has been previously described (Litwin et al. 2005) and explained by the nutritional status of the patients in the study. Recent studies of adults on chronic hemodialysis have shown that mild hypertension, hypercholesterolemia, and being overweight seem to be protective and are associated with improved survival (Nurmohamed and Nube 2005). This phenomenon has been named "reverse epidemiology" and is thought to be caused by a malnutritioninflammation-atherosclerosis complex.

To our knowledge, this is the first report of an inverse correlation between preclinical atherosclerosis and bilirubin in children with ESRD. Recent experimental and human studies have indicated that bilirubin plays an important role in cytoprotection as a physiological protector against oxidative stress damage (Sedlak and Snyder 2004). Oxidative stress is believed to play an important role in the development of the atherosclerotic process. Bilirubin in the serum may directly antagonize the oxidative stimuli within the blood stream and diminish their untoward effect on LDL particles (Neuzil and Stocker 1994). Thus, the negative correlation between serum bilirubin and preclinical atherosclerosis may indicate its important role as a physiological antioxidant in patients with ESRD.

We did not observe a correlation between preclinical atherosclerosis and any conventional cardiovascular risk factor under study, either in children with ESRD or in those in the control group. This finding could be caused by the different characteristics of the study populations, as a strong association was found in children of similar age but dialysed (Poyrazoglu et al. 2006, Civilibal et al. 2007) or in older children after renal transplantation (Bilginer et al. 2007). Therefore, the reason for the conflicting findings in our study could be due to the different durations of exposure to elevated blood pressure.

\section{Limitations and strengths of the study}

Some limitations of the study include its crosssectional design, the relatively low number of participants, and their heterogeneity due to different causes of renal failure and frequent pharmacological treatment. These factors may contribute to several marginal results and some differences between our work and previous studies. However, compared to other similar studies (Litwin et al. 2005, Bilginer et al. 2007), our study population consisted of almost the same number of patients with a less variable duration of transplantation. An additional strength of this study is the evaluation of a wide spectrum of conventional and nonconventional cardiovascular risk factors, including bilirubin levels and the atherogenic index of plasma.

\section{Conclusion}

In summary, based on our results, anti-oxidative capacity, as represented by serum albumin and bilirubin levels, may be important in the early development of atherosclerosis in children with end-stage renal disease, even those treated with transplantation and antihypertensive drugs. Therefore, management focused exclusively on conventional cardiovascular risk factors should not be the only method for lowering cardiovascular risk in this high-risk group of children.

Based on our data, further prospective clinical trials and studies focused on the management of cardiovascular disease in young patients with end-stage renal disease should also take into account the role of nutritional status and antioxidants.

\section{Conflict of Interest}

There is no conflict of interest.

\section{Acknowledgements}

This work was supported by the Centre for Cardiovascular Research (1M0510) and by the Czech Ministry of Health (grant NR 7900-5). Technical assistance from candidates of medicine Sugitha Sureshkumar and Romana Dembovska is gratefully acknowledged.

\section{References}

ATTMAN PO, SAMUELSSON O, ALAUPOVIC P: Progression of renal failure: role of apolipoprotein B-containing lipoproteins. Kidney Int Suppl 63: S98-S101, 1997. 
BERENSON GS: Childhood risk factors predict adult risk associated with subclinical cardiovascular disease. The Bogalusa Heart Study. Am J Cardiol 90: 3L-7L, 2002.

BILGINER Y, OZALTIN F, BASARAN C, AKI TF, KARABULUT E, DUZOVA A, BESBAS N, TOPALOGLU R, OZEN S, BAKKALOGLU M, BAKKALOGLU A: Carotid intima-media thickness in children and young adults with renal transplant: Internal carotid artery vs. common carotid artery. Pediatr Transplant 11: 888-894, 2007.

CIVILIBAL M, CALISKAN S, OFLAZ H, SEVER L, CANDAN C, CANPOLAT N, KASAPCOPUR O, BUGRA Z, ARISOY N: Traditional and "new" cardiovascular risk markers and factors in pediatric dialysis patients. Pediatr Nephrol 22: 1021-1029, 2007.

DOBIASOVA M, FROHLICH J: The plasma parameter log (TG/HDL-C) as an atherogenic index: correlation with lipoprotein particle size and esterification rate in apoB-lipoprotein-depleted plasma (FER(HDL)). Clin Biochem 34: 583-588, 2001.

GROOTHOFF JW, GRUPPEN MP, OFFRINGA M, DE GROOT E, STOK W, BOS WJ, DAVIN JC, LILIEN MR, VAN DE KAR NC, WOLFF ED, HEYMANS HS: Increased arterial stiffness in young adults with end-stage renal disease since childhood. J Am Soc Nephrol 13: 2953-2961, 2002.

JEHLICKA P, STOZICKY F, MAYER O Jr, VARVAROVSKA J, RACEK J, TREFIL L, SIALA K: Asymmetric dimethylarginine and the effect of folate substitution in children with familial hypercholesterolemia and diabetes mellitus type 1. Physiol Res 58: 179-184, 2009.

JOURDAN C, WUHL E, LITWIN M, FAHR K, TRELEWICZ J, JOBS K, SCHENK JP, GRENDA R, MEHLS O, TROGER J, SCHAEFER F: Normative values for intima-media thickness and distensibility of large arteries in healthy adolescents. J Hypertens 23: 1707-1715, 2005.

KAVEY RW, ALLADA V, DANIELS SR, HAYMAN LL, MCCRINDLE BW, NEWBURGER JW, PAREKH RS, STEINBERGER J: Cardiovascular risk reduction in high-risk pediatric patients: a scientific statement from the American Heart Association Expert Panel on Population and Prevention Science; the Councils on Cardiovascular Disease in the Young, Epidemiology and Prevention, Nutrition, Physical Activity and Metabolism, High Blood Pressure Research, Cardiovascular Nursing, and the Kidney in Heart Disease; and the Interdisciplinary Working Group on Quality of Care and Outcomes Research: Endorsed by the American Academy of Pediatrics. Circulation 114: 2710-2738, 2006.

KRONENBERG F, DIEPLINGER H, KONIG P, UTERMANN G: Lipoprotein metabolism in renal replacement therapy: a review. Isr J Med Sci 32: 371-389, 1996.

LILIEN MR, STROES ES, OP'T ROODT J, DE JONGH S, SCHRODER CH, KOOMANS HA: Vascular function in children after renal transplantation. Am J Kidney Dis 41: 684-691, 2003.

LITWIN M, WÜHL E, JOURDAN C, TRELEWICZ J, NIEMIRSKA A, FAHR K, JOBS K, GRENDA R, WAWER ZT, RAJSZYS P, TRÖGER J, MEHLS O, SCHAEFER F: Altered morphologic properties of large arteries in children with chronic renal failure and after renal transplantation. J Am Soc Nephrol 16: 1494-1500, 2005.

MCDONALD SP, CRAIG JC, THE AUSTRALIAN AND NEW ZEALAND PAEDIATRIC NEPHROLOGY ASSOCIATION: Long-term survival of children with end-stage renal disease. $N$ Engl J Med 350: 2654-2662, 2004.

MITSNEFES MM: Cardiovascular complications of pediatric chronic kidney disease. Pediatr Nephrol 23: 27-39, 2008.

MITSNEFES MM, KIMBALL TR, WITT SA, GLASCOCK BJ, KHOURY PR, DANIELS SR: Abnormal carotid artery structure and function in children and adolescents with successful renal transplantation. Circulation 110: 97-101, 2004.

NEUZIL J, STOCKER R: Free and albumin-bound bilirubin are efficient co-antioxidants for alpha-tocopherol, inhibiting plasma and low density lipoprotein lipid peroxidation. J Biol Chem 269: 16712-16719, 1994.

NURMOHAMED SA, NUBE MJ: Reverse epidemiology: paradoxical observations in hemodialysis patients. Neth $J$ Med 63: 376-381, 2005.

OH J, WUNSCH R, TURZER M, BAHNER M, RAGGI P, QUERFELD U, MEHLS O, SCHAEFER F: Advanced coronary and carotid arteriopathy in young adults with childhood-onset chronic renal failure. Circulation 106: 100-105, 2002. 
OREN A, VOS LE, UITERWAAL CS, BAK AA, GORISSEN WH, GROBBEE DE, BOTS ML: The atherosclerosis risk in young adults (ARYA) study: rationale and design. Eur J Epidemiol 18: 715-727, 2003.

PAREKH RS, CARROLL CE, WOLFE RA, PORT FK: Cardiovascular mortality in children and young adults with end-stage kidney disease. J Pediatr 141: 191-197, 2002.

PIGNOLI P, TREMOLI E, POLI A, ORESTE P, PAOLETTI R: Intimal plus medial thickness of the arterial wall: a direct measurement with ultrasound imaging. Circulation 74: 1399-1406, 1986.

PITHA J, KRAJICKOVA D, CIFKOVA R, HUBACEK J, PETRZILKOVA Z, HEJL Z, STAVEK P, SKIBOVA J, POLEDNE R: Intima-media thickness of carotid arteries in borderline hypertensives. $J$ Neuroimaging 9: 19-22, 1999.

POYRAZOGLU HM, DÜSÜNSEL R, YIKILMAZ A, NARIN N, ANARAT R, GÜNDÜZ Z, COSKUN A, BAYKAN A, ÖZTÜRK A: Carotid artery thickness in children and young adults with end stage renal disease. Paediatr Nephrol 22: 109-116, 2007.

QUERFELD U: Disturbances of lipid metabolism in children with chronic renal failure. Pediatr Nephrol 7: 749-757, 1993.

RAITAKARI OT: Imaging of subclinical atherosclerosis in children and young adults. Ann Med 31 (Suppl 1): 33-40, 1999.

RITZ E: Why are lipids not predictive of cardiovascular death in the dialysis patient? Miner Electrolyte Metab 22: 9-12, 1996.

SARNAK MJ, LEVEY AS, SCHOOLWERTH AC, CORESH J, CULLETON B, HAMM LL, MCCULLOUGH PA, KASISKE BL, KELEPOURIS E, KLAG MJ, PARFREY P, PFEFFER M, RAIJ L, SPINOSA DJ, WILSON PW: Kidney disease as a risk factor for development of cardiovascular disease: a statement from the American Heart Association Councils on Kidney in Cardiovascular Disease, High Blood Pressure Research, Clinical Cardiology, and Epidemiology and Prevention. Circulation 108: 2154-2169, 2003.

SASS C, HERBETH B, CHAPET O, SIEST G, VISVIKIS S, ZANNAD F: Intima-media thickness and diameter of carotid and femoral arteries in children, adolescents and adults from the Stanislas cohort: effect of age, sex, anthropometry and blood pressure. J Hypertens 16: 1593-1602, 1998.

SCHWARTZ GJ, HAYCOCK GB, EDELMANN CM Jr, SPITZER A: A simple estimate of glomerular filtration rate in children derived from body length and plasma creatinine. Pediatrics 58: 259-263, 1976.

SEDLAK TW, SNYDER SH: Bilirubin benefits: cellular protection by a biliverdin reductase antioxidant cycle. Pediatrics 113: 1776-1782, 2004.

SEEMAN T, DUSEK J, VONDRAK K, SIMKOVA E, KREISINGER J, FEBER J, JANDA J: Ambulatory blood pressure monitoring in children after renal transplantation. Transplant Proc 36: 1355-1356, 2004.

URBANOVA Z, SAMANEK M, CESKA R, CIFKOVA R, POLEDNE R, ROSOLOVA H, SOSKA V, SIMON J, VAVERKOVA H, WIDIMSKY J Jr, WIDIMSKY J Sr, ZADAK Z: Recommendations for the diagnosis and therapy of hyperlipoproteinemia in childhood and adolescence developed by the Committee of the Czech Society for Atherosclerosis. (in Czech) Cas Lek Cesk 137: 89-92, 1998.

WENDELHAG I, GUSTAVSSON T, SUURKULA M, BERGLUND G, WIKSTRAND J: Ultrasound measurement of wall thickness in the carotid artery: fundamental principles and description of a computerized analysing system. Clin Physiol 11: 565-577, 1991.

YANG XZ, LIU Y, MI J, TANG CS, DU JB: Pre-clinical atherosclerosis evaluated by carotid artery intima-media thickness and the risk factors in children. Chin Med J (Engl) 120: 359-362, 2007. 